\title{
Gaps and Common Misconceptions in Public's Food Safety Knowledge
}

\author{
Kathy Kim ${ }^{1}$, Helen Heacock ${ }^{2}$ \\ ${ }^{1}$ Lead Author, B. Tech Student, School of Health Sciences, British Columbia Institute of Technology, 3700 Willingdon Ave, Burnaby, BC V5G \\ $3 \mathrm{H} 2$ \\ ${ }^{2}$ Supervisor, School of Health Sciences, British Columbia Institute of Technology, 3700 Willingdon Ave, Burnaby, BC V5G 3H2
}

\begin{abstract}
Background: Incidence rates of some foodborne illnesses (FBIs) in BC still remain on the rise despite numerous initiatives to prevent FBIs. This rise over the years has been attributed to gaps in the public's food-safety knowledge and practices. In order to decrease incidence rates and prevent future FBIs, efforts should be made to identify common misconceptions in the public's food safety knowledge. With a focus on the Metro Vancouver population, common misconceptions in food safety were found and their knowledge level towards the misconceptions was analyzed.

Methods: An in-person survey was conducted in three locations in Metro Vancouver. The survey asked for demographics information, perceived food safety knowledge and food safety misconceptions. ANOVA and Independent Sample T-test were administered to analyze results.

Results: No statistically significant difference in food safety knowledge was found between groups by gender, age, and geographic region. The majority of participants rated their food safety knowledge as moderate but they demonstrated a poor knowledge level in food safety.

Conclusion: The public's knowledge level should be improved to prevent further rises of FBIs. Initiatives involving the provincial Foodsafe certification program, secondary school curriculums and health authority websites can be utilized to educate the public.
\end{abstract}

Keywords: food safety, misconceptions, knowledge, foodborne illness

\section{INTRODUCTION}

Recent food outbreaks may have raised food safety awareness among public, but incidence rates of some foodborne illnesses, such as salmonellosis, shigellosis, Vibrio and norovirus infection, still remain on the rise (1). Despite numerous programs and initiatives to reduce the number of foodborne illnesses (FBIs) in Canada, approximately one out of three Canadians experience a FBI every year (2). FBIs pose a significant threat to public health, and its rise over the years has been attributed to the gaps in the public's food-safety knowledge and practice $(3,4)$. Purchasing, preparing, cooking, and eating are routine practices of everyday life, and the decisions ones make in food-handling and consumption are highly dependent on their food safety knowledge. Well-informed food safety knowledge will help in the prevention of foodborne illness, but ill-informed misconceptions regarding food safety can lead to adverse outcomes. This research study was conducted for the purpose of evaluating food safety knowledge of the Metro Vancouver population with a goal to help health professionals better understand the gaps in current food safety interventions implemented in $\mathrm{BC}$ and inform potential strategies to address them. 


\section{LITERATURE REVIEW}

\section{Common Misconceptions In Food Safety}

The importance of why this study is focusing on the misconceptions as opposed to the general knowledge should be addressed. Many existing studies have determined the public knowledge level of food-safety. For example, one study examined knowledge levels about food safety in a cohort of Irish persons and revealed that the majority of this population perceived less-thanideal practices in kitchen to be safe (3). Some examples of such practices included defrosting raw meat on the kitchen counter, eating fruit and vegetables without washing them, and leaving the leftover food overnight on the kitchen counter (3). A similar study done in Ontario, Canada, assessed food safety knowledge among undergraduate students at the University of Waterloo and discovered that the majority of students did not know how to properly prepare leftover food (4). The studies that assess food safety knowledge thus identify the gaps in foodsafety knowledge in general public, and offer some possible explanations for why such gaps may be present. To further determine the public's food safety knowledge in Metro Vancouver, only the selected misconceptions that seem to be recurring in the segment of population will be discussed in this paper. From past studies and the information acquired from instructors of the BCIT Environmental Health program, a collection of common misconceptions in food safety was analyzed. It is important to correct misconceptions related to food safety, as they could result in high risk behaviors among people handling food, thereby increasing the likelihood of FBI of those individuals and people around them. By identifying the common misconceptions in food safety and assessing the public knowledge of the misconceptions, more direct and comprehensive answers can be communicated to the public rather than simply recommending the best practice.

\section{Misconception 1. Washing raw poultry removes germs}

There is a common belief among some that they need to wash raw chicken before cooking $(5,6)$. According to a study conducted in U.S. through a nationally representative web survey of adult grocery shoppers, nearly $70 \%$ of consumers reported washing raw poultry before cooking it (7). Many believe that washing the raw poultry will eliminate any unwanted debris and germs. However, this is not true as washing poultry can splash the contaminated water, which could transfer onto other kitchen surfaces and other food items (7).

\section{Misconception 2. Cooked foods should be cooled to room temperature before being placed in the fridge}

There also is a common misconception that cooked foods should be cooled to room temperature before putting them into the refrigerator $(5,8)$. One study found that $24 \%$ participants stored cooked food in the refrigerator after first cooling to room temperature (9). Improper cooling is a very risky practice and it is known as the number one leading cause of FBI (10). This can be dangerous as the food is left at the temperature range known as the "danger zone" in which foodborne illness pathogens can multiply quickly.

\section{Misconception 3. Color is a good indicator of doneness in meats and poultry}

Many people do not know that color is not a good indicator of doneness in meats and poultry $(5,7,11)$. Past studies have shown that visual inspection can be risky $(5,12)$ and one study 
found that $70 \%$ of the chicken meat which consumers judged as fully cooked was indeed undercooked and contained active Campylobacter jejuni cells (13). Relying on the color of the meat can be a hit-or-miss system, and thus it is considered as an unsafe practice. Use of a thermometer is recommended as the required temperature of $74^{\circ} \mathrm{C}$ can be checked by inserting the thermometer into the thickest part of the meat $(2,10)$. Reaching $74^{\circ} \mathrm{C}$ will ensure the destruction of $99.9 \%$ of pathogens (2).

\section{Misconception 4. Following recipes ensure the safety of the food}

Many cookbooks and recipes are shared among family, as well as via internet and media. However, it is important to understand that following recipes will not necessarily guarantee the safety of the food. Recipes often present color as an indicator of doneness in meat and they rarely give endpoint temperature $(5,14,15)$. This relates to the previous misconception that color is a good indicator of doneness. Another study from Philadelphia also found that old recipes usually give instructions to wash poultry in order to remove the slime off of the justopened chicken (16). People with limited cooking experience tend to strictly follow recipes, which are not always written by an author who has completed an official food safety course. Therefore, recipes should be checked and followed with special caution.

\section{Misconception 5. Thawing raw meats in room temperature is safe}

Despite numerous interventions to educate the public about proper thawing or defrosting of frozen raw meats, many people still thaw their meat on the kitchen counter (3). One study where the participants were interviewed about their home kitchen practices found that $62.7 \%$ of the participants defrost meat and fish at room temperature compared to $27.2 \%$ who defrost in the refrigerator (9). It is not recommended to thaw frozen food at room temperature as it can expose the food to the danger zone temperature range in which most bacteria will multiply (10). Alternative methods such as thawing in a refrigerator or cold water, as well as using a microwave oven are safe as they minimize the time the food is left in the danger zone (10).

\section{Misconception 6. Raw milk is safe to drink}

Raw milk is known to be more nutritious than the pasteurized milk, but many people do not know that it is unsafe to drink raw milk. One study done in Northern Colorado about raw milk consumers' attitudes found that they disagreed with government information on raw milk and considered raw milk to be safe (17). They believed that raw milk is more natural and more healthful (17). However, raw milk can be contaminated with urine, feces, and other environmental contaminants from the source animal (18). Thus, it can contain pathogens such as Listeria, Salmonella, E.coli O157:H7, and Campylobacter, which can potentially result in deadly foodborne illnesses (18). Without any thermal process (pasteurization) to kill such pathogens, milk cannot be guaranteed safe to drink. In fact, raw milk is categorized as a high risk food in Canada, and Canada's Federal Food and Drugs Regulation clearly states that raw milk is illegal to be sold in Canada (18).

\section{Misconception 7. Reheating food will make the food safe to eat}

One common misconception is that reheating food will make the food safe to eat.

Microwaving is a very convenient and fast way to reheat food. However, inadequate reheating poses a foodborne illness risk and can be a concern with microwave use $(19,20)$. There are 
two conditions to be met when reheating food: The time the food has been sitting in room temperature should not exceed 2 hours and the temperature should have reached at least $74^{\circ} \mathrm{C}$ (10). A study conducted in Ontario found that most highschool students did not know the proper temperature of reheating leftovers, although many of them knew that leftovers should be refrigerated within 2 hours $(4,21)$. Furthermore, uneven heat distribution must also be taken into account when using a microwave, which can result in hot and cold spots (22). Lastly, pathogens such as Staphylococcus aureus and Bacillus cereus can produce heat-stable toxins that can possibly emerge in the food after 2 hour period in the danger zone (22). Therefore, reheating food without considering time and temperature factors would be unsafe.

\section{Misconception 8. Cooked eggs with runny yolks are safe to eat}

Runny yolks are a health concern but people often do not recognize eggs as a potentially hazardous food. Cooking eggs with runny yolks is a popular method to prepare eggs because it enhances the smoother texture and the stronger flavor of the yolk. However, according to Foodsafe, the yolk has to be hard and not runny when it has been safely cooked (10). Since eggs can be contaminated with Salmonella, raw eggs should be handled the same way as someone would handle a raw chicken (10).

\section{Misconception 9. Breaded and browned frozen chicken nuggets indicate that they have been pre-cooked}

There have been numerous foodborne illnesses related to frozen chicken nuggets. In April and May of 2017, a Salmonella outbreak linked to frozen, raw chicken nuggets occurred across 4 provinces in Canada (23). Three more Salmonella outbreaks occurred in Canada during
2014 and 2015 with uncooked, frozen and processed chicken nuggets (24). In Minnesota, US, there were 4 Salmonella outbreaks associated with raw, frozen, microwaveable, breaded, pre-browned, stuffed chicken products from 1998 to 2006 (25). Likewise, frozen raw chicken nuggets are often associated with Salmonella contamination. The raw "flash fried" chicken products are not guaranteed to be free of bacteria (26). Thus, it is crucial to cook the chicken nuggets thoroughly before consumption. However, there is a high chance for the public to assume that all chicken nuggets are fully cooked because they have the pre-cooked appearance with breaded and pre-browned coatings, and when they are cut open, they do not appear to be obviously rare or uncooked (26).

\section{Misconception 10. Thoroughly washing a dish sponge with dish detergent and letting it completely dry ensures the sponge is effectively cleaned}

It is not an exaggeration to say that dish sponges are one of the dirtiest and unhygienic items that can be found in households. Nevertheless, they come into the closest contact with food contact surfaces such as cutting boards and various kitchen utensils. Food scums that act as nutrients and the moisture in the sponge are sufficient to support the growth of microorganisms (27). Dish detergent alone is not effective in cleaning the sponge as it does not achieve the safe level of bacteria reduction. In households, it is recommended to heat the contaminated sponge for 1 minute in a microwave or boil the sponge in water for 5 minute; these methods can achieve $99.9 \%$ reduction in the number of bacteria (27).

\section{Misconception 11. Towel drying is the recommended method to dry your dishes}

Due to the convenience of saving the time to dry dishes, dish towels are commonly used to dry 
dishes. However, this practice can be risky as dish towels are often heavily contaminated. Kitchen towels can quickly and easily become contaminated. In fact, a study revealed that towels are the most contaminated of all food contact surfaces tested (28). This study also showed how people touched kitchen towels before washing their hands and after washing their hands inadequately, re-contaminating their just-washed hands (28). Likewise, because of their wide means of use such as wiping hands, drying counters and dishes, dish towels can harbor many bacteria leading to foodborne illnesses. Instead, air drying is the recommended way to dry dishes $(10,29)$.

\section{Other Misconceptions}

Other than the ones that were previously mentioned, there are many more common misconceptions in food safety which people believe to be true. Some examples are "The last food you ate is the one you made you sick" and "It is safe to eat your hamburger undercooked if you grind the meat on your own at home". For the scope of this literature review and the lack of documented research in these particular topics, it is apparent that not every misconception has been addressed in detail.

\section{MATERIALS AND METHODS}

\section{Materials}

A consent form, a Google Forms survey and a cover letter were created electronically. The surveys were distributed by hard copies. Collected data was recorded by Microsoft Excel, and the data was analyzed using Number Crunching Statistical System (NCSS) statistical software. As an incentive to participate in the study, three prizes from BCIT (portable USBs) were offered to the participants.

\section{Methods}

The surveys were delivered in-person using hard copies. The survey consisted of 15 questions with 4 questions for descriptive statistics and 11 questions for knowledge assessment. The descriptive statistics section obtained information about the age, gender, living region of the participants, and their perceived food safety knowledge level. The knowledge assessment section contained a series of 11 trueor-false statements that examines participants' food safety knowledge, and the questions generated multichotomous nominal responses of true, false or unsure options. Each correct answer was worth 1 mark and incorrect or unsure answers received 0 mark. The marks were added up to represent the total score out of 11 for each respondent.

The surveys were delivered to 34 participants who were randomly selected at 3 locations (BCIT, Pacific Centre, Willowbrook Shopping Centre) in Metro Vancouver during the study period (Jan 13, 2018 - Feb 1, 2018).

Using the survey data, the participants were divided into groups based on their geographical regions, gender and age. ANOVA and Independent Sample T-test were performed using NCSS to analyze the results.

\section{Use of Established Protocol}

As a measure to increase the validity of the study design, various references were used to create the survey. Some of the questions in the descriptive statistics section are brought from Statistics Canada 2016 Census of Population questions (30), and the knowledge assessment questions were adopted from previous studies that have been covered in the literature review. 


\section{Inclusion and Exclusion Criteria}

All persons living in Metro Vancouver visiting Pacific Centre, Willowbrook Shopping Centre, and BCIT on study days were eligible to participate in this study. People living outside of Metro Vancouver who were not present at the specified locations on study days were excluded from the list.

\section{Ethical Considerations}

Confidentiality and anonymity of the participants were protected. The participants were informed that the participation is voluntary, and the consent form was provided before the survey to describe the nature of the study, benefits and burdens, study procedures and how the data will be used. There was no known harm in participating in the study.

\section{RESULTS}

\section{Descriptive Statistics Analysis}

Total of 34 persons residing in Metro Vancouver completed the survey. The most prevalent age group that participated in the survey was the age group of 20-29 years old. This represented $44.1 \%$ of the respondents (Figure 1). Following age groups were 50-59 (17.6\%), 30-39 (11.8\%), $40-49(11.8 \%), 19$ and under $(8.8 \%)$, and 60 and over $(5.9 \%)$ respectively.

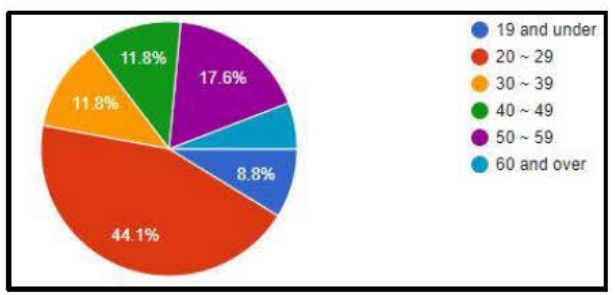

Figure 1. Descriptive statistics of age distribution of the participants
In terms of gender distribution, there were more females $(58.8 \%)$ than males (41.2\%) (Figure 2).

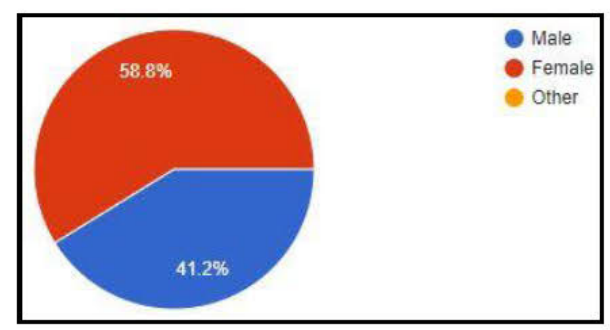

Figure 2. Descriptive statistics of gender distribution of the participants

In regards to geographical distribution within Metro Vancouver, half (50\%) of the participants were living in Zone 3, 26.5\% in Zone 1, and $23.5 \%$ in Zone 2 (Figure 3).

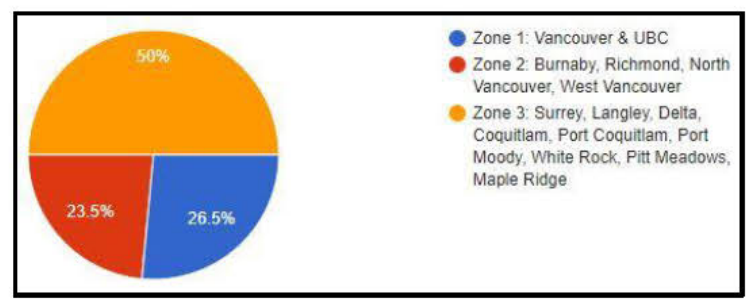

Figure 3. Descriptive statistics of geographical distribution of the participants

The majority $(73.5 \%)$ of the participants rated their food safety knowledge as moderate. $20.6 \%$ of the participants rated their food safety knowledge as high, and only 5.9\% said their food safety knowledge is low (Figure 4).

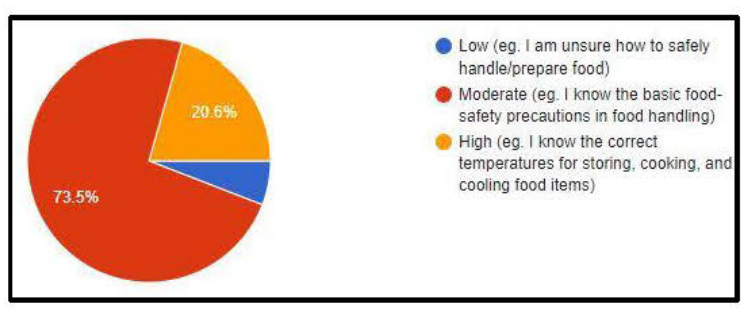

Figure 4. Descriptive statistics of the anticipated food safety knowledge level of the participants

\section{Inferential Statistics Analysis}

The scores from the knowledge assessment section were recorded for each set of groups: 
[Zone 1, Zone 2, Zone 3], [Female, Male], [Age under 30, 30 and over]. ANOVA and Independent Sample T-test were conducted to compare the means of the scores among the groups.

The results showed that there was no statistically significant difference in food safety knowledge scores between the groups in every set. The $\mathrm{p}$ values of the different geographic region, gender and age groups were $0.166,0.241$ and 0.450 respectively.

\section{DISCUSSION}

Although the difference was not statistically significant among the three geographical regions (Zone 1, Zone 2, Zone 3), the mean scores of knowledge assessment section of each zone were 5.3, 5.9 and 6.8 respectively (out of 11). These minor differences could be explained by demographic variance among the participants in every zone group as well as the number of surveys done in each area, and relatively small sample size overall.

The absence of statistically significant results between males and females was contradictory to past studies that reported females tend to have higher level of food-safety knowledge (3-4,9). This difference has been explained by the tendency of females to participate in foodhandling practices such as grocery shopping and cooking more frequently than males $(3,9)$. No statistically significant difference between different age groups was also contradictory to previously documented studies (4-5, 31-32). Past studies state that young demographics $(<30$ years) were more likely to mishandle food than older demographics, and this, in part, contributes to the increased incidence of foodborne illness among younger age groups $(4,33)$. Possible reasons for this phenomenon are that younger populations are more likely to consume ready- to-eat (RTE) products, have less exposure to public education of food safety, and lack experience in food handling (34-35).

The results from the analyses contradicting previous findings could be due to the survey's small sample size as well as different demographics compared to the referenced studies. None of the previous studies have covered the topic of food safety misconceptions among the general Metro Vancouver population in $\mathrm{BC}$.

In terms of self-assessment of food-safety knowledge, $73.5 \%$ (25 out of 34 ) rated their food-safety knowledge as moderate, $20.6 \%$ (7 out of 34 ) as high, and only $5.9 \%$ (2 out of 34 ) rated low. However, the overall mean score of the knowledge assessment of the 34 participants was 6 out of $11(54.5 \%)$. This indicates that the participants answered almost half of the foodsafety misconception questions incorrectly, which implies they were either ill-informed or not knowledgeable of the information. Some of the misconception statements which recorded the highest number of incorrect answers will be discussed below:

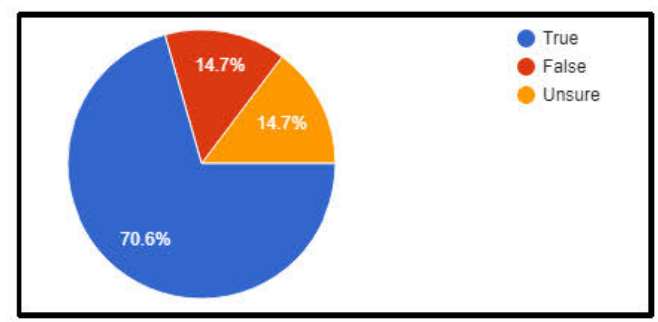

Figure 5. Responses summary of "Cooked foods should be cooled to room temperature before being placed in the fridge"

$70.6 \%$ answered True and $14.7 \%$ were unsure of the answer for this misconception. This indicates that over $85 \%$ of the participants either did not know or knew incorrect information regarding safe cooling practices. 


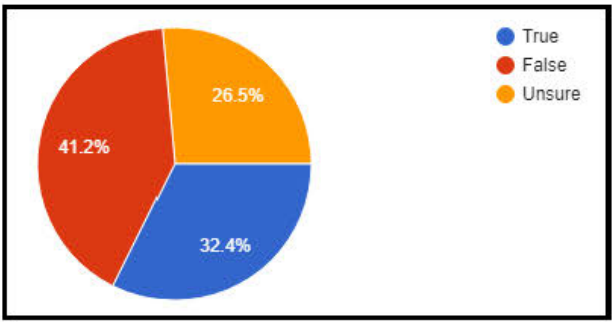

Figure 6. Responses summary of "Raw (unpasteurized) milk is safe to drink"

$32.4 \%$ believed that raw milk is safe to drink and $26.5 \%$ reported that they were unsure. The high percentage of the participants who chose the Unsure option shows that many of the participants were unfamiliar with raw milk; some of them did not know what raw milk is.

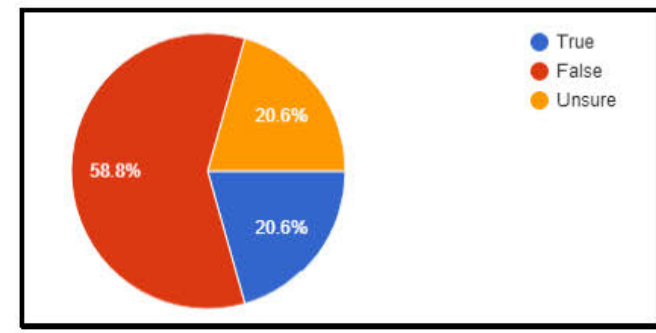

Figure 7. Responses summary of "It is unsafe to eat cooked eggs with runny yolks"

$58.8 \%$ chose False and $20.6 \%$ chose Unsure. As a result, nearly $80 \%$ of the participants answered incorrectly and did not know that a runny yolk is unsafe to eat. It can imply that the practice of cooking eggs with runny yolks has become so common that many do not identify it as food that can be harmful to human health.

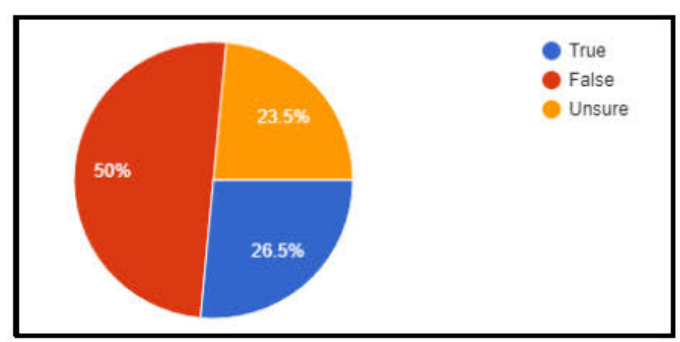

Figure 8. Responses summary of "Breaded and browned chicken nuggets indicate that they have been pre-cooked"
Only half of the participants correctly answered this statement by selecting False. It shows that many still rely on the appearance of the food product rather than reading the label to decide whether a cooking step is required or not. This is particularly of a concern given that reports of foodborne illnesses associated with eating chicken nuggets (23-26).

All other survey questions were answered correctly by the majority $(>50 \%)$ of the participants. However, every question had incorrect and unsure answers chosen by the participants, which clearly implies that there are gaps existing in food safety knowledge or misconceptions among Metro Vancouver population. Strategies to improve any knowledge deficiency will be discussed in the knowledge translation section.

\section{KNOWLEDGE TRANSLATION}

No statistically significant difference in foodsafety knowledge among different study groups suggests that education is vital to dispel foodsafety misconceptions regardless of people's age, gender and where they live. As tools to deliver information and educate the public, knowledge translation strategies such as Foodsafe certification programs, school curriculums, and health authority websites, can be implemented.

Incorporating such educational tools with foodsafety fact sheets and information revisions that can easily deliver food safety messages will improve the public's exposure to accurate information and equip them with knowledge to distinguish true food-safety facts from myths. Foodsafe certification programs are available and often required for anyone who is interested in becoming a food-handler in commercial kitchens. School textbooks provide information to young students who might not have enough 
experience and knowledge about food safety. Health authority websites can provide answers to anyone who is curious enough to search in media about food-safety related topics. Hence, these knowledge translation strategies can help everyone including those in higher risk groups to have more opportunities to learn food safety.

\section{LIMITATIONS}

Due to the nature of the survey method (inperson survey) and the lack of time to administer the surveys, the number of participants was small (34 participants). A small sample size cannot be fully representative of the Metro Vancouver population and, thus, limits the validity of the study. The generated data from the analysis cannot be directly extrapolated to the population's food-safety knowledge.

Only three sites were visited to administer the survey, and this could have also impacted the validity of the study. The sites were chosen to represent each of the zones used to divide the study groups. However, one shopping mall or one post-secondary school cannot be representative of the whole zone which includes numerous Metro Vancouver cities.

\section{FUTURE RESEARCH}

Based on the results of the study, further research in this topic can be pursued. A similar survey can be conducted to cover a larger geographical area such as BC rather than just Metro Vancouver, and also an online survey method can be used to allow larger sample size.

In addition, the misconception statements can be developed based on one topic area such as food safety in households, food safety in dining or food safety in outdoor barbeque.

\section{CONCLUSION}

The results from the study suggest that there is no statistically significant difference in foodsafety knowledge among Metro Vancouver population based on the differences in age, gender and geographical region. Although the majority of participants rated their food-safety knowledge as moderate, the overall knowledge assessment score showed that their food-safety knowledge level is poor. In order to improve the public's knowledge level in food-safety misconceptions, strategies such as a revision of Foodsafe certification program, secondary school curriculums and health authority websites are recommended. These media can be utilized as educational tools to translate food-safety knowledge to the public in Metro Vancouver as this will help them to learn and acknowledge correct information from common food-safety misconceptions. Ultimately, an improved general knowledge level of food safety will prevent further foodborne illnesses in this population.

\section{ACKNOWLEDGEMENTS}

The author thanks British Columbia Institute of Technology, Environmental Health department, and the instructor of ENVH 8410 course Helen Heacock for her support and help as a supervisor of this research study.

\section{COMPETING INTEREST}

The author declares that she has no competing interests.

\section{REFERENCES}

1. Communicable Disease Prevention and Control Services (CDPACS). British Columbia Annual Summary of Reportable Diseases. 2015;1-128. 
2. Fraser Health. Food Safety At Home [Internet]. 2017 [cited 2017 Oct 20]. Available from: http://www.fraserhealth.ca/healthinfo/health-topics/food-safety/food-safetyat-home/

3. McCarthy M, Brennan M, Kelly AL, Ritson $\mathrm{C}$, de Boer M, Thompson N. Who is at risk and what do they know? Segmenting a population on their food safety knowledge. Food Qual Prefer. 2007;18(2):205-17.

4. Courtney SM, Majowicz SE, Dubin JA. Food safety knowledge of undergraduate students at a Canadian university: results of an online survey. BMC Public Health [Internet]. 2016;16(1):1147. Available from: http://bmcpublichealth.biomedcentral.com/a rticles/10.1186/s12889-016-3818-y

5. Byrd-Bredbenner C, Berning J, MartinBiggers J, Quick V. Food safety in home kitchens: A synthesis of the literature. Int $\mathbf{J}$ Environ Res Public Health. 2013;10(9):4060-85.

6. Henley SC, Stein SE, Quinlan JJ. Identification of Unique Food Handling Practices That Could Represent Food Safety Risks for Minority Consumers. J Food Prot [Internet]. 2012;75(11):2050-4. Available from: http://jfoodprotection.org/doi/abs/10.4315/0 362-028X.JFP-12-146

7. Kosa, K. M., Cates, S. C., Bradley, S., Chambers, 4., Edgar, \& Godwin S. Consumer-reported handling of raw poultry products at home: Results from a national survey. J Food Prot. 2015;78(1):180-6.

8. Bruhn CM, Schutz HG. Consumer Food Safety Knowledge and Practices. J Food Saf. 1999;19(0):73-87.

9. Langiano E, Ferrara M, Lanni L, Viscardi V, Abbatecola AM, De Vito E. Food safety at home: Knowledge and practices of consumers. Journal of Public Health. 2012;20(1):47-57.

10. Burton, T., Wilcott, L., Egeler, J., Steacy K. Foodsafe Level 1, Participant Workbook. 5th edition. British Columbia. Ministry of Advanced Education; 2014.

11. Maughan C, Chambers IV E, Godwin S, Chambers D, Cates S, Koppel K. Food Handling Behaviors Observed in Consumers When Cooking Poultry and Eggs. J Food Prot [Internet]. 2016;79(6):970-7. Available from: http://openurl.ingenta.com/content/xref?genr $\mathrm{e}=$ article \&issn $=0362-$

$028 X \&$ volume $=79 \&$ issue $=6 \&$ spage $=970$

12. Kennedy, J; Gibney, S; Nolan, A; O’Brien, S; McMahon, M.; McDowell, D; Fanning, S; Wall P. Identification of critical points during domestic food preparation: an observational study. Br Food J. 2011;113(6):766-83.

13. Bergsma, Nynke J; Fischer, Arnout R.H; Van Asselt, Esther D; Zwietering, Marcel H; De Jong AE. Consumer food preparation and its implication for survival of Campylobacter jejuni on chicken. Br Food J. 2007;109(7):548-61.

14. McCurdy SM, Takeuchi MT, Edwards ZM, Edlefsen M KD, Mayes VE HV. Food safety education initiative to increase consumer use of food thermometers in the United States. Br Food J. 2006;108(9):775-94.

15. Mathiasen LA, Chapman BJ, Lacroix BJ, Powell DA. Spot the Mistake : Television Cooking Shows as a Source of Food Safety Information. Food Prot Trends. 2004;24(6):328-34.

16. Ewing R. "Don't Wash Your Chicken" Video Vignettes Make Cooking Safer [Internet]. DrexelNOW. 2015 [cited 2017 Oct 22]. Available from: http://drexel.edu/now/archive/2013/August/ Dont-Wash-Your-Chicken-Food-SafetyCampaign/

17. Markham L, Auld G, Bunning M, Thilmany D. Attitudes and Beliefs of Raw Milk Consumers in Northern Colorado. J Hunger Environ Nutr [Internet]. 2014;9(4):546-64. Available from: http://dx.doi.org/10.1080/19320248.2014.92 9542

18. BCCDC. Raw Milk [Internet]. 2017 [cited 2017 Oct 19]. Available from:

http://www.bccdc.ca/health-info/food-yourhealth/dairy/raw-milk

19. Majowicz SE, Diplock KJ, Leatherdale ST, Bredin CT, Rebellato S, Hammond D, et al. Food safety knowledge, attitudes and selfreported practices among Ontario high school students. Can J Public Heal. 2015;106(8):e520-6.

20. Mody RK, Meyer S, Trees E, White PL, Nguyen T, Sowadsky R, et al. Outbreak of Salmonella enterica serotype I 4,5,12:i:infections: the challenges of hypothesis generation and microwave cooking. Epidemiol Infect [Internet]. 2014;142(5):1050-60. Available from: 
http://www.journals.cambridge.org/abstract S0950268813001787

21. Stein SE, Dirks BP, Quinlan JJ. Assessing and addressing safe food handling knowledge, attitudes, and behaviors of college undergraduates. J Food Sci Educ. 2010;9(2):47-52.

22. Motarjemi, Y., Moy, G., Todd, E. C. D., \& Knovel A. Food Science. In: Encyclopedia of food safety. 1st ed. Boston: Academic Press Inc.; 2013.

23. Newstex Trade \&Industry Blogs; Chatham. Food Safety : Loblaw s recalls chicken nuggets linked to News Salmonella outbreak [Internet]. 2017. Available from: http://ezproxy.library.ubc.ca/login?url=https ://search.proquest.com/docview/19182\%0A 33662 ? accountid $=14656$

24. Hobbs JL, Warshawsky B, Maki A, Zittermann S, Murphy A, Majury A, et al. Nuggets of Wisdom: Salmonella Enteritidis Outbreaks and the Case for New Rules on Uncooked Frozen Processed Chicken. J Food Prot [Internet]. 2017;80(4):703-9. Available from: http://jfoodprotection.org/doi/10.4315/0362028X.JFP-16-431

25. Smith KE, Medus C, Meyer SD, Boxrud DJ, Leano F, Hedberg CW, et al. Outbreaks of salmonellosis in Minnesota (1998 through 2006) associated with frozen, microwaveable, breaded, stuffed chicken products. J Food Prot. 2008;71(10):215360.

26. Kenny B, Hall R, Cameron S. Consumer attitudes and behaviours--key risk factors in an outbreak of Salmonella typhimurium phage type 12 infection sourced to chicken nuggets. Aust N Z J Public Health [Internet]. 1999;23(2):164-7. Available from: http://www.ncbi.nlm.nih.gov/pubmed/10330 731

27. Ikawa JY, Rossen JS. Reducing bacteria in household sponges. J Environ Health. 1999;62:18-22.

28. Kansas State University. Towels top kitchen contamination hazards list [Internet]. Science Daily. 2015 [cited 2018 Jan 9]. Available from: https://www.sciencedaily.com/releases/2015 /03/150318144502.htm

29. Zablocki E. Air Dry Your Dishes [Internet]. WebMD. 2001 [cited 2018 Jan 9]. Available from: https:/www.webmd.com/a-to-zguides/news/20010817/air-dry-yourdishes\#1
30. 2016 Census of Population questions, long form (National Household Survey)

[Internet]. www12.statcan.gc.ca. 2017 [cited 23 November 2017]. Available from: http://www12.statcan.gc.ca/nhsenm/2016/ref/questionnaires/questionseng.cfm

31. Nesbitt A, Majowicz S, Finley R, Marshall B, Pollari F, Sargeant J, et al. High-risk food consumption and food safety practices in a Canadian community. J Food Prot. 2009;72(12):2575-86.

32. Altekruse SF, Yang S, Timbo BB, Angulo FJ. A multi-state survey of consumer foodhandling and food-consumption practices. Am J Prev Med. 1999;16(3):216-21.

33. Majowicz SE, Doré K, Flint JA, Edge VL, Read S, Buffett MC, et al. Magnitude and distribution of acute, self-reported gastrointestinal illness in a Canadian community. Epidemiol Infect. 2004;132:607-17

34. Slater J. Is cooking dead? The state of home economics food and nutrition education in a Canadian province. Int J Consum Stud. 2013;37:617-24. 25.

35. Renzetti E. Cutting home economics? Now that's out to lunch. The Globe and Mail [Internet]. 2014; Available from: https://www.theglobeandmail.com/opinion/c utting-home-economics-now-thats-out-tolunch/article18231363/

36. Byrd-BredBenner C, Maurer J, Wheatley V, Schaffner D, Bruhn C, Blalock L. Food safety self-reported behaviors and cognitions of young adults: results of a national study. J Food Prot. 2007;70(8):1917-26. 